\title{
THE CRISIS MANAGEMENT PRACTICES OF AUSTRALIAN CONSTRUCTION COMPANIES
}

\author{
M. Loosemore, University of New South Wales \\ M. M. M. Teo, Building Construction Authority, Singapore
}

\section{INTRODUCTION}

Events such as September $11^{\text {th }}$, high-profile corporate collapses such as $\mathrm{HIH}$, the subsequent turmoil in our insurance industry and the recent financial reporting debacle in the USA, have acted as a stark and sudden reminder of the unpredictability of the world around us and of the construction industry's vulnerability to it. Those companies that have over relied on insurance to manage uncertainty are now counting the costs and are being forced to review their risk management practices by financers and insurance companies that are reconsidering their risk coverage, reducing claim payments and increasing their fees (Lawson, 2002). While risk management is increasingly practised in the construction industry, al beit in an unsophisticated way, knowledge of crisis management practices is less widespread (Loosemore, 2000). Given the current security concerns surrounding major buildings and infrastructure in Australia, this is an aspect of risk management which justifies special attention at the moment. However, even in "normal" times, it is an area of practice to which construction companies should give more attention.

Organisational crises are a special type of risk which manifest themselves into decisive periods of acute difficulty that threaten the viability of an organisation, its business units or key products and even the lives of people (Fink, 1986; Aguilera and Messick, 1986). They are low probability, high impact events which create the need for critical and rapid analytical decision-making skills, the results of which are likely to fall under extensive public, media and/or government scrutiny (Perrow, 1984; Pauchant and Mitroff, 1992; Irving, 1997; Pearson and Clair, 1998). Consequently, crises are characterised by an extreme sense of urgency which hyper-extend an organisation's coping capabilities, producing stress and anxiety among organisational actors and stakeholders (Allen, 1990; Pearson et al., 1997).
Although most companies would prefer to avoid a crisis, there is an increasing realisation that crises are becoming an inevitable and healthy part of organisational life, which have to be planned for (Frazer and Hippel, 1984; Pascale, 1993; Furze and Gale, 1996; Lerbinger, 1997). This planning should be part of an integrated and thoroughly implemented risk management process but evidence suggests that many organisations exist in a low state of crisis preparedness, having an inadequate understanding of their risk exposure, of how to mitigate those risks and of the internal systems needed to cope with and learn and recover from their eventuality. While crises can destroy unprepared organisations they can strengthen those that are well prepared since a well conceived crisis management plan should harness potential opportunities as well as ensure survival (Pascale, 1993; Furze and Gale, 1996).

It is within this context that an investigation of the crisis preparedness of construction companies was undertaken in Sydney. The objectives were to gauge attitudes towards crisis management and the adequacy of systems used to plan for and manage them.

\section{The signs of crisis proneness}

All construction companies are prone to crisis but to different extents, depending upon the nature of work they are engaged in. For example, a company involved in large complex inner city projects is likely to be more prone to crises than a company involved in house building. However, this is largely dependent upon the way an organisation is managed and Pauchant and Mitroff (1992), Mitroff and Pearson (1993) and Person et al. (1997) have found that crisis- prone organisations have certain characteristics in common. In particular, they tend to be sceptical about risk management and characterised by a culture of managerial invincibility and fatalism. Such organisations also tend to have task-orientated cultures which consistently stress the importance of profits 
over other corporate goals. The mind-set that is nurtured is that crises are essentially negative in nature, that company size and past successes provide protection from future crises, that crises happen to others, that good management and hard work prevents crises and that desirable business ends justify the taking of high-risk business means. People in crisis-prone organisations also believe that crisis management is someone else's responsibility and that they have the power to offload risks onto other parties, thereby insulating themselves from their environment. For these organisations, crisis management plans are considered a sign of weakness because crises are seen as a sign of managerial failure. To a crisisprone organisation, there is little justification for the re-examination of existing organisational practices in the aftermath of a crisis, and rather than learning lessons for the future the priority is to maintain the organisation's public image and to ensure that internal operations remain intact.

In essence, crisis-prone organisations have an inappropriate structure and culture in relation to their risks and do not dedicate sufficient resources to proactive crisis management planning. Consequently, crisis management plans represent little more than a managerial façade and have minimal impact upon day-to-day organisational practices and attitudes. As Mitroff and Pearson (1993, xvii) point out, "in such organisations, CM (crisis management sic) activities may be designed to fool everyone, but ultimately they fool no one at all".

\section{Crisis-prepared organisations}

In contrast to crisis-prone organisations, those which are prepared have a culture of openness, awareness and sensitivity to organisational risks and of their social and financial responsibilities to stakeholders and the wider environment (Ginn, 1989; Lerbinger, 1997; Pearson et al., 1997). Proactive risk management is systematically incorporated into strategic planning processes and championed by senior executives so that it is an integral part of organisational life at all levels (More, 1995). In this sense, senior executives provide the drive and support for crisis management by providing sufficient resources and clear statements of fundamentally held core beliefs and attitudes relating to organisational priorities. For example, crisis-prepared organisations often have a permanent crisis management team, charged with the responsibility of creating a comprehensive crisis management plan and to continuously communicate, coordinate and review crisis management efforts. As Osborne (1991) argues, centrally co-ordinated guidance is critical in creating corporate attitudes and managerial inclinations that are able to unite an organisation in a decisive and immediate crisis response at a time of strong divisive and procrastinating forces.

Another characteristic of crisis-prepared organisations is their flexibility and willingness to "let go" of formal, standardised systems and procedures which serve them well in normal times but which become restrictive and counter-productive during a crisis (Mintzberg, 1976; Sagan, 1991). However, total flexibility may result in a loss of managerial control and a disjointed crisis response, meaning that a delicate balance between formality and informality is necessary. Such a balance facilitates effective horizontal and vertical communications with external and internal stakeholders at a time when existing information systems are stressed to the limit. During a crisis, effective communication is essential but difficult and companies with a track record of effective communication as an intrinsic part of their day-to-day life are most likely to survive (Mindszenthy et al., 1988; Aspery and Woodhouse, 1992; Sikich, 1993). Effective communication systems are particularly important in dealing with external stakeholders such as emergency services, the public, the media and existing and potential customers. The media, in particular, play an important role in constructing the public's image of events, and poor communications can result in distortions of the truth, unjustified mistrust, suspicion and irrevocable damage to customer relations. In essence, a crisis-prepared organisation has well developed and widely understood crisis management plans which keep them in constant touch with what type of crisis it faces, when they begin, why they occur and who they affect (Mitroff and Pearson, 1993). It is the state of knowledge in these areas which represents the fundamental difference between crisis-prone and crisis-prepared organisations. 


\section{Crisis management planning}

The importance of a well-conceived crisis management plan cannot be overstated and it represents one of the defining characteristics of a crisis-prepared organisation. This has been illustrated many times, such as in the Occidental Piper Alpha disaster where appropriate operating manuals on how to interrupt a potentially catastrophic sequence of events were almost totally lacking (Bea, 1994). Having a preconceived plan that can be automatically implemented takes away some of the initial pressure and shock associated with the early phases of a crisis. This creates a valuable "breathingspace" within which people can calmly investigate the problem and agree on an appropriate response. The importance of a good start in crisis management cannot be over-stated. During a crisis, every second counts and the first few hours are particularly critical. This is especially true if external constituencies are involved because initial impressions play a disproportionately large role in shaping their judgments of competence and blame. If initial impressions are bad then an organisation will be judged guilty until proven innocent and in many instances this can intensify a crisis and accelerate its escalation (Loosemore, 2000).

Many organisations in high-risk industries have a permanent disaster committee that is responsible for championing the need for crisis management, identifying current preparedness and vulnerabilities, devising disaster plans, and coordinating people during a crisis (Kutner, 1996). The membership of such committees is an important factor in determining their ability to do this, and they should consist of senior managers, managers from all functional departments, and external professionals who have experience of crisis management, public relations, the law, and physical and mental health issues. In particular, commitment from the top of an organisation is essential if the activities of a disaster committee are to be taken seriously and if they are to have a chance of success. The various aspects of these activities are discussed below.

\section{Conducting crisis audits and creating crisis} portfolios

A crisis audit assesses an organisation's crisis capabilities and identifies the inherent risk factors in its environment, internal activities, technology, infrastructure, and culture that need to be addressed to improve its crisis preparedness (Mitroff and Pearson, 1993). The first stage in this process should be to develop a working definition of a crisis from the organisation's viewpoint and to then identify and rank, in probability and consequence terms, the types of crises the organisation is vulnerable to. This involves learning from past events, looking into the future and exploring unusual combinations of events that may seem unlikely, but could combine to produce a serious crisis. Ranking allows appropriate judgments to be made about the relative costs and benefits of constructing a crisis management plan in each case because planning for every possible crisis is not economically rational.

Establishing monitoring systems and standard operating procedures

One aspect of the disaster committee's job is to establish monitoring systems to detect potential crises. The disaster committee should also develop standard procedures that define precisely who should be involved in a crisis response, what they should be doing, when they should be doing it, and how they should be doing it. These procedures, in effect, establish a pre-defined emergency communication network that needs to be followed during a crisis' early but critical phases, when people are disorientated by events. The intention is to "buy" the organisation some time to come to terms with events, to allow people to re-orientate themselves, and to ensure that appropriate resources are mobilised quickly and that they are commensurate with a crisis' scale. To do this, the procedures should be achievable, simple, flexible, and understandable by all internal and external stakeholders. For example, in Australia and Singapore, construction sites have many migrant workers and this may require the production of manuals in a range of different languages.

\section{Creating a command centre}

During a crisis, information is constantly being generated from a multitude of sources and it is critical that it is supplied "live" to the correct place, at the correct time, and in an understandable format (Davis, 1995). In this sense, a key aspect of a disaster committee's job during a crisis is to identify a clear command centre that represents a single point of responsibility for 
decision-making and information management. Such centres are a critical coordination mechanism that helps facilitate a unified crisis management effort since one of the greatest problems that can emerge during a crisis is the tendency for people to act independently. For example, in the case of a fire emergency, the command centre should have the sole responsibility for contacting emergency services and to coordinate individual supervisors who are charged with clearing certain areas of the site. In the case of an economic crisis, such as the bankruptcy of a major subcontractor, the command centre should be responsible for re-organizing work and employing another sub-contractor. In addition to being of practical importance during a crisis, command centres also play an important symbolic role. Nicodemus (1997) provides an example of a company that faced a crisis and named their command centre "the war room," where they declared war on the problem.

\section{Security}

Security is another important issue for a disaster committee to consider since interference from unwanted elements can exacerbate a crisis or, at the very least, interfere with its management. This involves identifying external constituencies who feel that they have a stake in a crisis' outcome but who cannot contribute to its solution. While all stakeholders must be managed and kept informed, those involved in crisis management efforts should be insulated from these disruptive elements so they can develop a strong focus on the problem.

In some situations, it is also important that the site of a crisis is physically cut off from these elements, particularly when it continues to represent a danger to the public. In such situations, evacuation procedures may need implementing and it is essential that they are clearly communicated to everyone on a project and reinforced by regular training and mock drills. For example, public address systems, sirens and horns can be used to notify people of an incident if they are placed at strategic locations so everyone can hear them. Whatever signal is used, it must be as simple and as unequivocal as possible. Responsibilities for using them must be clear, as should appropriate back up if, as Murphy's Law dictates, key people are away on the day of an incident or if essential equipment malfunctions. An important part of evacuation is the clear labelling of exit routes from all parts of the site. In particular, people should know that mechanical hoists cannot not be used in an evacuation and that all potentially dangerous machinery in the vicinity of escape routes must be switched off. Since a construction site is a constantly changing physical environment, the positions of notices and their maintenance needs constant monitoring. Furthermore, all evacuation routes should follow the shortest possible route to checkpoints where roll calls can be taken in safety. They should also be wide enough to facilitate an orderly evacuation of the building. On inner city sites this may be the street, and the hazards to the public, to traffic, and to site workers must be assessed in association with public services such as the police.

The potential danger of not having adequately thought out evacuation plans and well-marked evacuation routes was demonstrated in the Beverly Hills Supper Club fire in May 1977 which killed 164 people. The official investigation report reveals that the club had no evacuation plan and that employees were not schooled or drilled in the duties they were to perform in the case of fire. Furthermore, means of egress were not marked and the escape route itself was too narrow to take the number of people who were in the building at that particular point in time (Best, 1977).

\section{Devel oping a culture of collective} responsibility

The need to insulate a disaster response team from unwanted elements does not mean it should be allowed to become introverted. Consideration also needs to be given to the re-organisation of non-crisis management activities so the remainder of an organisation can function as normally as possible. Crises inevitably drain a considerable amount of energy from other functional areas within an organisation, demanding special efforts from the people who operate there. Clearly, without a considerable degree of peripheral goodwill and a sense of collective responsibility, the impact of a crisis can spread to other parts of an organisation. Such goodwill cannot be expected if it did not exist before a crisis, and in this sense the crisis management process needs to be continuous. 
One way of developing a culture of collective responsibility is to communicate everyone's interdependency during a crisis and to clarify and, ideally, share project risks as much as possible. Most crises demand an injection of extra resources into a project and if the disaster committee does not identify their source in advance, then a crisis will stimulate negotiations and potential conflicts that will delay a response.

Decisions concerning risk distribution are particularly relevant to economic crises, and earlier we provided evidence to suggest that they have been a major cause of conflict within construction projects. We also identified a series of principles to guide risk decision-making. These principles apply at all points along the contractual chain, and to consultants as well as contractors. It is also important to realise that the client's initial risk management practices are inevitably transferred along the contractual chain. For example, if a contractor is employed under a high-risk contract and has not been given the opportunity to price for those risks, then it is likely that they will attempt to transfer those risks along the chain by using backto-back contracts and similar employment practices with their sub-contractors. Indeed, sub-contractors may do the same and so on, until all project risks have been dissipated to the end of the contractual chain. Unfortunately, it is here that the most vulnerable, crisis-prone organisations exist, and when problems begin to occur that demand extra resources, the end result of this risk-cascade is inevitably a backlash of conflict up the contractual chain as parties deny any responsibility for them.

Public relations

Public relations are an essential aspect of crisis management since most types of crises have implications beyond an organisation's boundaries. In essence, the three "publics" that need to be involved in a crisis are employees not directly affected by it, external and quasi-external interest groups and the general public. We have already discussed the first two publics and it would be foolish to ignore the third. As Aspery (1993, p. 18) argues, "crisis communications built on well-established relationships with key audiences stand a better chance of protecting, even enhancing your reputation during difficult times. A company which decides to start communicating during a crisis will have little credibility'.
Unfortunately, construction companies tend to attach little importance to the building of sound relationships with the media, seeing it as a non value-adding activity and perceiving most journalists as dangerous, untrustworthy, and irresponsible (Moodely and Preece, 1996). This rejection of the media tends to be particularly strong during a crisis when organisations look inward and consciously hide from the public, seeing them as an unnecessary distraction to rescue efforts. However, this is precisely the time when it is most dangerous to ignore the media, since in the aftermath of a crisis, the public has a tendency to embark on a process of ritual damnation. This is particularly true of high-profile, publicly financed projects in which people may feel a greater right to recrimination as a result of having paid their taxes to finance it. As HorlickJ ones (1996, p. 61) notes, "since the abolition of capital punishment, the British public has turned to those in charge during lurid disasters to satisfy its lust for retribution. Find someone to blame, cries the mob, and off runs Whitehall to offer up someone for lynching". Poor public relations have been the downfall of many organisations that have underestimated the power of the media in shaping public opinion of how a crisis is being handled.

The media

The construction industry is particularly vulnerable to poor media coverage because of its very negative public image. Furthermore, there is increasing scrutiny of the industry as a result of the ever-greater appreciation of its impact on the built and natural environment (Moodley and Preece, 1996). This, coupled with growing sympathies with the environmental movement amongst the general population, has resulted in increasing numbers of confrontations with the public, particularly on large infrastructure, mining and housing projects. Notably, in many of these increasingly common and public confrontations, the media has portrayed construction companies in a heavy-handed and unsympathetic way and there is little doubt that the future viability of many projects will have been affected by this coverage. In this sense, media relations is an area of traditional neglect to which companies operating in the construction industry must turn their attention. Construction managers cannot rely upon the media to put their case and a continued reluctance to communicate with 
the media will almost certainly lead to negative reporting of the industry's activities. In contrast, open relationships with the press and more sensitivity to environmental issues will enable managers to better shape the public's attitudes and thereby obtain a more balanced presentation of the facts from the media during a crisis.

One way of ensuring open communication with the press during a crisis is to establish a 24-hour-a-day press office, which has the responsibility of providing factual and up-todate information to the media and to employees. If managed well, such an office should be able to turn media inquiries into opportunities rather than problems by initiating, rather than reacting to, press, radio, and TV coverage. Public relations are best handled by one trained person who is named as an official spokesperson and who has skills in dealing with the media. TV interviews with untrained staff who appear uncaring, flustered and unsure of the facts are damaging to the public's perception of competence whereas a trained person with experience of such events can portray a positive image. The importance of identifying such a person was illustrated during the aftermath of the TWA flight 800 crash when the rush of distraught families, an eager press, and an interested public were left to the management of one chief ticket agent who, through no fault of his own, released inaccurate information which fuelled uncertainty, anxiety and false speculation about the handling of the affair (Bobo, 1997). This was a primary reason for TWA being widely criticised afterward by public relations counsellors, crash victims' families and the media for having an uncaring attitude.

\section{Post-crisis management}

After a crisis, a disaster committee should organise follow-up meetings so lessons can be learned and fed into subsequent crisis management efforts. Everyone affected by a crisis must be involved in this process. In addition to managing the learning process, the disaster committee should also turn its attention to the recovery. This can be a lengthy and sensitive process that is likely to be influenced by how well a crisis was managed. For example, it may involve delicate challenges such as conducting investigations into causes, mending damaged relationships, re-organizing the project program, settling on-going disputes and reassessing project requirements. At the same time, attention must be given to the long-term consequences of a crisis such as rectifying damage to the environment, or dealing with government or legal investigations. Clearly, the less effectively a crisis is managed, the more arduous is the recovery process.

\section{Research method}

Mitroff and Pearson (1993) provided a conceptual framework for investigating crisisproneness and understanding the major factors which contribute to effective crisis management. Essentially, they argued that effective crisis management is determined by:

- Attitudes towards crisis management and the extent to which an organisation understands the types of crises which it should prepare for, given its mission and its industry.

- The extent to which an organisation resources crisis management activities and effectively manages the five distinct phases through which all crises pass, namely, signal detection, preparation and prevention, damage containment, recovery and learning.

- The extent to which priorities and interactions between the technological, the individual/human and the organisational/cultural systems are understood and managed.

- The relative perceptions of organisational responsibilities to external and internal stakeholders.

On the basis of these factors, Mitroff and Pearson produced a diagnostic model which identified the factors in an ideal crisis management program (See Table 1): 
Table 1: Factors in an ideal crisis management (CM) program (Adapted from Mitroff and Pearson 1993, p.114)

\begin{tabular}{|c|c|}
\hline $\begin{array}{l}\text { Elements of an integrated } \\
\text { crisis management } \\
\text { program }\end{array}$ & $\begin{array}{l}\text { Key questions to ask in an integrated crisis management } \\
\text { program }\end{array}$ \\
\hline Strategic actions & $\begin{array}{l}\text { Is crisis management integrated into corporate philosophy, } \\
\text { mission statements, strategic planning and notions of corporate } \\
\text { excellence? } \\
\text { Is there a dedicated CM unit or team? } \\
\text { Are outsiders included on the Board and/or CM unit team? } \\
\text { Is training conducted in CM? } \\
\text { Are there regular crisis simulations? } \\
\text { Are there any diversification and portfolio strategies? }\end{array}$ \\
\hline $\begin{array}{l}\text { Technical and structural } \\
\text { actions }\end{array}$ & $\begin{array}{l}\text { Has a dedicated budget for CM been created? } \\
\text { Are steps taken to continually develop and change emergency } \\
\text { policies and manuals? } \\
\text { Are there computerised inventories of plant, employees, } \\
\text { products and capabilities? } \\
\text { Is there a strategic emergency room or facility? } \\
\text { Are steps taken to reduce hazardous products, services and } \\
\text { production processes? } \\
\text { Are steps taken to improve overall design and safety of products } \\
\text { and production? } \\
\text { Is there technological redundancy (such as computer backup)? } \\
\text { Are outside experts and services in CM used? }\end{array}$ \\
\hline $\begin{array}{l}\text { Evaluation and diagnostic } \\
\text { actions }\end{array}$ & $\begin{array}{l}\text { Are legal and financial audits of threats and liabilities } \\
\text { conducted? } \\
\text { Are there continuous reviews and modifications of insurance } \\
\text { policies and coverage? } \\
\text { Are environmental impact audits conducted? } \\
\text { Is there ranking of the most critical activities necessary for daily } \\
\text { operations? } \\
\text { Is there any early warning signal detection, scanning and issues } \\
\text { management system in place? } \\
\text { Is there dedicated research on potential hidden dangers? } \\
\text { Is there critical follow- up and learning from past crises? }\end{array}$ \\
\hline Communication actions & $\begin{array}{l}\text { Is there media training for CM? } \\
\text { Are there major efforts in public relations? } \\
\text { Is there extensive information on local communities? } \\
\text { Are there good relationships with intervening stakeholder } \\
\text { groups? } \\
\text { Is there extensive collaboration and lobbying among } \\
\text { stakeholders? } \\
\text { Are new communication technologies and channels used? }\end{array}$ \\
\hline $\begin{array}{l}\text { Psychological and cultural } \\
\text { actions }\end{array}$ & $\begin{array}{l}\text { Is there strong top management commitment to CM? } \\
\text { Are there good relationships with activist groups? } \\
\text { Are whistleblowers accepted? } \\
\text { Is there access to knowledge of potential criminal behaviour? } \\
\text { Is the human and emotional impact of crises recognised? } \\
\text { Is there psychological support for employees? } \\
\text { Is there stress management and management of anxiety? } \\
\text { Is there a corporate memory of past crises and dangers? }\end{array}$ \\
\hline
\end{tabular}


Table 2: Sample company profiles

\begin{tabular}{|l|l|l|l|}
\hline Company & Workforce & $\begin{array}{l}\text { Annual Turnover } \\
\text { (AU\$mill) }\end{array}$ & $\begin{array}{l}\text { Company age } \\
\text { (years) }\end{array}$ \\
\hline A & 112 & 60 & 80 \\
\hline B & 300 & 250 & 72 \\
\hline C & 600 & 900 & 47 \\
\hline D & 400 & 300 & 42 \\
\hline E & 1000 & 1500 & 40 \\
\hline
\end{tabular}

On the basis of Mitroff and Pearson's diagnostic model and key questions, semistructured interviews were conducted with fourteen senior managers, in five large and well-established international construction companies based in Sydney, Australia. Company documents relating to crisis management systems were also inspected. Those interviewed were selected because of their seniority and specific responsibility for risk management in their company. This targeted sampling strategy ensured that respondents had a good understanding of their organisation's crisis management systems. The purpose of the interviews was to investigate attitudes towards crisis management activities and the adequacy of any existing crisis management systems.

The company profiles are provided in Table 2 and were selected because their risk exposures would justify crisis management policies of a sophistication equivalent to those advocated in Mitroff and Pearson's model. Smaller companies involved in relatively low risk projects would not justify systems of the type advocated by Mitroff and Pearson.

\section{DISCUSSION OF RESULTS}

What follows is a general discussion of the strengths and deficiencies which emerged in the crisis management planning of the sampled companies. These are organised around attitudes towards crisis management, resources dedicated to crisis management activities and learning processes instigated during the aftermath of crises.

Attitudes towards crisis management $56 \%$ of respondents believed that crises were inevitable and $65 \%$ believed it possible and worthwhile to plan for their eventuality. Although this indicates reasonably low levels of managerial complacency, $28 \%$ had considerable sympathy with the idea that crises could be eliminated and $21 \%$ considered it difficult to plan for their eventuality. Their attitude was that it was best to respond to crises as they arose and that crisis plans were best developed on an ad hoc basis in response to the peculiar problems which each crisis presented. These respondents also felt that insurance provisions were adequate to cover the costs of a crisis, an attitude which is all too typical in the construction industry. This reliance upon insurance is worrying given recent world events and research which indicates that the average insurance payout only covers approximately $60 \%$ of the costs of an insured event (Odeyinka, 2000). Even more worrying was the belief that crisis management was a specialised activity that was the province of very large companies in higher risk industries and that policies of not overcommitting to excessive workloads or single contracts, above a certain proportion of turnover, insulated them from the occurrence of serious crises. The respondents were working in the largest $5 \%$ of companies in one of Australia's most high-risk industries.

Resources for crisis management

There was no evidence in any company of permanent crisis management teams and little evidence of any corporate crisis management planning. Rather, crisis management was treated as a reactive activity and the assumption was made that in the event of a crisis, the organisation would be able to respond adequately with existing resources and that plans could be created "on-thespot". Crisis management planning was at best rudimentary, crisis plans taking the form of general informal procedures and "unwritten policies" incorporated into the mainstream operating procedures of each company. The vast majority of managerial effort had been invested in the formulation of "company policies" for health and safety problems (46\%) industrial relations disputes $(40 \%)$ and IT failure (14\%), rather than in detailed contingency plans. 
Although there was little evidence of thorough crisis management planning, two companies had attempted to create workimprovement teams to facilitate communication between different functional areas, and with union delegates, and to enable employees to highlight potential problems with, and solutions and improvements for working practices. However, respondents felt that company cultures were unsympathetic to the communication of "bad news" and that this largely mitigated the benefits of such activities. To avoid this problem, one company had developed plans through a consultative team that permitted workers to voice their concerns with impunity so that issues could be raised before they became a potential threat.

Crisis management training was also rare, although in one company chief executives had undergone extensive media and worstcase scenario training and had experienced simulations of potential crises. Similarly, another company held risk-awareness workshops every six months for chief executives. However, in all cases such training was insular, being confined to the most senior levels, thereby limiting its potential value and impact. Only one company had an integrated communications policy, which involved issuing strict guidelines to all organisational levels about dealing with the media. This company also provided lists of emergency phone numbers for contact during a crisis, and specialised training at all organisational levels, particularly in the areas of industrial relations and health and safety but not specifically in crisis management. None of the companies maintained regular and planned contact with external stakeholder groups, all confining policy communications with personnel employed on a consistent basis in their normal day-today activities. In this sense, little account seemed to be taken of a company's potential impact upon and responsibilities to the emergency services, general community, minority groups and the environment.

\section{Learning from past crises}

$93 \%$ of respondents were aware of past crises, causes being classified as accidents (46\%), economic conditions (38\%), disputes (industrial and others) (8\%) and financial management (8\%). Those with direct experience of these past crisis indicated that the problems of crisis management had been in damage containment rather than in detection, because they had been largely anticipated in existence but not in impact. However, two companies had tackled this problem in the area of industrial disputes by developing plans to prevent them spreading between sites. In terms of learning and recovering from crises, the general perception was that this was a natural long-term process which necessitated little assistance. However, there was considerable evidence to indicate that learning had become a problem in many of the companies. Despite there being widespread confidence in being less vulnerable to similar future crises (58\%), few of the interviewees had direct experience of past crises and had only become aware of them through company "folklore" and informal communication networks. Furthermore, although there was a widespread (65\%) and encouraging perception that the uniqueness of crises does not preclude lessons being learnt for the future, only $8 \%$ of respondents had any knowledge or experience of an organised learning process in the aftermath of a past crisis or were able to provide details of consequent changes to company procedures. As one respondent said, learning from a crisis "is the biggest job that we don't do" and those changes that were highlighted by respondents were considered to be relatively minor and part of an ongoing process of evolutionary development. Other evidence of crisis vulnerability exists in comments which directly reflect the rationalisations discovered by Mitroff and Pearson (1993) that hinder effective crisis management. For example, $65 \%$ of respondents considered that their companys size afforded protection against crises. Only one respondent saw a crisis as "a unique learning process" which provided a test of its plans and "an opportunity to improve its plans". Finally, most respondents considered that most crises were caused by the actions of an individual who may, for unknown reasons, have uncharacteristically made an error in performing a task. This reflected a widespread belief that past crises had been "freak" events which were beyond managerial control and that existing systems had, and would, continue to avert many other crises.

\section{CONCLUSION}

The study reported within this paper explored the crisis preparedness of five large, international construction companies operating within Australia. Due to the limited 
sample, the extent to which the mindsets and systems that were discovered predominate within the construction industry is unclear. However, considering the relatively high levels of risk to which these types of companies are exposed, the investigation suggests that their state of crisis preparedness is inadequate and unlikely to improve without external intervention. Corporate philosophies evidenced in this study do not seem to support crisis management and there exists a predominant attitude that a long-standing record of continued survival is sufficient justification for maintaining the status quo. Furthermore, there appears to be a general belief that effective risk management practices can and should eliminate crises. The contemporary and alternative belief that crises are an inevitable and healthy part of organisational life is not widely espoused. Essentially, crisis management does not appear to be taken seriously and is undertaken in an informal, fragmented fashion with few resources and little strategic guidance and support. The limited activities that are undertaken are preventative in focus and give little consideration to coping with the eventuality of a crisis. Furthermore, they are insular and non-integrative in their development, being confined to senior management and are limited in scope to issues such as safety, industrial relations and, to a lesser extent, cost control. They also appear to be limited to a narrow range of stakeholders and to largely ignore the impact of a crisis upon the wider community. In essence, there appears to be relatively little effort invested in exploring the full range of risks which face companies at their various hierarchical levels, little understanding of the interdependency between these risks and little attempt to plan for their eventuality.

Mitroff and Pearson's (1993) work suggests, that in the construction companies investigated in this research, a crisis would be likely to stimulate a period of reactionary chaos, social dislocation and disjointedness, at least in the short term. During this period, which would prevent any rational and coordinated response, costs would escalate and people would be guided by unwritten rules and procedures and information provided through informal communication networks. The managerial challenge during this period would be to re-establish an element of control and co-ordination in people's activities by attempting to communicate policies which may have been developed in isolation at a senior managerial level, if at all. However, in the dynamic environment of a construction firm, communication is difficult, but particularly so during the pressures and high stakes of a crisis. Indeed, if the source of a crisis is at site level, then these problems would be further exacerbated by the obscurity of relationships between crisis planning at site and company level and by the need to coordinate the activities of sub-contracted organisations with a wide range of conflicting interests.

While many construction companies may have survived and indeed prospered for some time with the above mindset, continued success in an increasingly changeable and competitive world will demand the elimination of potential resource wastage and the maximisation of potential opportunities. Highly successful companies are able to turn problems to their advantage and fully exploit any opportunities they encounter. Crisis management capabilities are important in this respect because crises present both threats and opportunities and mismanagement can impart a heavy monetary and psychological toll upon an organisation and in extreme cases, destroy its viability. Complacency is dangerous and it is evident that construction companies could benefit from systematically incorporating crisis management activity as a part of their strategic planning process so that it is an integral and continuous part of organisational life at all levels. Such a change needs to be driven by senior management, supported by appropriate resources and guided by clearly explicated mission statements of central core beliefs, attitudes and organisational priorities and well conceived, fully integrated crisis management strategies, systems and procedures. There is also a role for research in bringing about this change. In particular, research is needed into how to make the construction industry's culture more optimistic, less inwardly and short-term orientated, and less cost-driven. Such research would have to be broad-ranging and cover issues such as employment and contractual practices, methods of organisation and procurement systems, attitudes towards risk and risk management practices, training, education, the nature of construction markets and corporate strategy. 


\section{REFERENCES}

Aguilera, D. C. and Messick, J . M. (1986) Crisis intervention: Theory and methodology. C V Mosby Company, St Louis, USA.

Allen, R. E. (1990) The Concise Oxford Dictionary of current English. Clarendon Press, Oxford, UK.

Argyris, C. (1990) Oercoming organisational defenses. Allyn and Bacon, London, UK.

Aspery, J. (1993) The media: friend or foe? Administrator 2 (2), 17-19.

Aspery, J . and Woodhouse, N. (1992) Strategies for survival. Management Services, 36 (11), 14-16.

Bea, R.G. (1994) The role of human error in design, construction, and reliability of marine structures. Ship Structure Committee SSC-378, U.S. Coastguard, Washington, DC.

Best, R. L. (1977) Reconstruction of a tragedy. The Beverly Hills Supper Club Fire. Southgate, KY: National Fire Protection Association.

Bobo, C. (1997) Hitachi faces crisis with textbook response. Public Relations Quarterly 42 (2), 18-21.

Brown, M. (1993) The disaster business. Management Today, October, 42-48.

Fink, S. (1986) Crisis management: Planning for the inevitable. American Management Association, New York, USA.

Frazer, N. M. and Hippel, K. W. (1996) Conflict analysis: Models and resolutions. North Holland, New York, USA.

Furze, D. and Gale, C. (1996) Interpreting management exploring change and complexity. International Thompson Business Press, London, UK.

Galbraith, J. R. (1977) Organisation design. Addison-Wesley, New York, USA.

Ginn, R. D. (1989) Continuity planning: Preventing, surviving and recovering from disaster. Elsevier Science Publishers Ltd, Oxford, UK.

Gonzalez-Herrero, A. and Pratt, C. B. (1995) How to manage a crisis before-or whenever-it hits. Public Relations Quarterly, 40 (1), 25-29.

Green, S. (1998) The technocratic totalitarianism of construction process improvement: a critical perspective. Engineering,
Construction and Architectural Manage ment, 5 (4), 376-386.

Horlick-J ones, T. (1996) The problem of blame. In: Hood, C. and J ones, D.K.C. (eds) Accident and design: Contemporary debates in risk management. UCL Press, London, 61-70.

Irvine, R. B. (1997) What's a crisis anyway?: Surviving a business crisis. Glanbridge Publishing Ltd, Illinios, USA.

Kutner, M. (1996) Coping with crisis. Occupational Health and Safet,y65 (2), 22-24.

Lawson, M. (2002) September 11 spurs new era for insurance. The Australian Financial Review, Wednesday $10^{\text {th }}$ April.

Lerbinger, O. (1997) The crisis manager: Facing risk and responsibility. Lawrence Erlbaum Associates Publishers, New Jersey, USA.

Loosemore, M. (2000) Crisis management in construction projects. American Society of Civil Engineers Press, New York, USA.

Mindszenthy, B. J., Watson, T. A. G. and Koch, W. J . (1988) No surprises: The Crisis communications management system. Bedford House Publishing Ltd, Ontario, Canada.

Mitroff, I. and Pearson, C. (1993) Crisis management: $A$ diagnostic guide for improving your organisation's crisis preparedness. J ossey-Bass Publishers, San Fransisco, USA.

Moodley, K. and Preece, C.N. (1996) Implementing community policies in the construction industry. In: Langford, D.A. and Retik, A. (eds) The Organisation and Management of Construction. London: $\mathrm{E}$ and $\mathrm{F} \mathrm{N}$ Spon: 178-86.

More, E. (1995) Crisis management and communication in Australian organisations. Australian J ournal of Communication, 22 (1), 31-47.

Nicodemus, J . 1997. Operational crisis management. Secured Lender 53 (6), 84-90.

Odeyinka, H. A. (2000) An evaluation of the use of insurance in managing construction risks. Construction Management and Economics, 18 (5), 519-525.

Osborne, R. L. (1991) Core value statements: the corporate compass. Business Horizons, September/October, 29-34. 
Pascale, R. T. (1991) Managing on the edge. Penguin Books, Harmondsworth, UK.

Pauchant, T. C. and Mitroff, I. (1992) Transforming the crisis-prone organisation: Preventing individual, organisational and environmental tragedies. J ossey-Bass Publishers, San Fransisco, USA.

Pearson, C. M. and Clair, J. A. (1998) Reframing crisis management. Academy of Management Review, 23 (1), 59-76.

Pearson, C. M., Misra, S. K., Clair, J . A. and Mitroff, I. (1997) Managing the unthinkable. Organisational dynamics, 26 (2), Autumn, 51-64.

Perrow, C. (1984) Normal accidents: Living with high risk technologies. Basic Books, Inc. Publishers, New York, USA.

Preece, C. N., Moodley, K. and Smith, A. M. (1998) Corporate communications in construction. Blackwell Science, Oxford, UK.

Richardson, B. (1996) Modern management's role in the demise of a sustainable society. Journal of Contingencies and Crisis Management, 4 (1), March, 20-31.

Rubin, D. K., Campbell, J . and Lawson, M. (1988) From collapses to corruption: Managing company crises. ENR, 11 (1), February, 28-37.

Seymour, D. and Rooke, J. (1995) The culture of the industry and the culture of research. Construction Management and Economics, 13 (4), 511-523.

Sikich, G. W. (1993) It can't happen here: All hazards crisis management planning. PennWell Publishing Company, Oklahoma, USA. 